2. Rosta J, Aasland OG. Changes in the lifetime prevalence of suicidal feelings and thoughts among Norwegian doctors from 2000 to 2010: a longitudinal study based on national samples. BMC Psychiatry 2013; 13: 322.

\section{Re: Kommuniserbar sykdom}

Jeg er enig i at mediene kan påvirke folks helse negativt, slik Sigurd Høye skriver på lederplass i Tidsskriftet nr. 3/2015 (1). Vi tenker sjelden på hva som skjer med mennesker som via medier får servert grusomme inntrykk fra alle kanter av verden. Tragiske bilder og tekster fra naturkatastrofer og kriger fyller TV-skjermer og førstesider $\mathrm{i}$ avisene. Tilskuere og lesere er emosjonelt og etisk nødt til å ta stilling til ubehagelige saker. Grusomme bilder vekker reaksjoner og kan traumatisere folk som ikke har evne til å bearbeide så store mengder ondskap og smerter. Grupper som mediene stigmatiserer kan få dårlig kvalitet på livet og helsen (2), og bli værende i en tilstand hvor de er i beredskap for å forsvare seg.

Jeg har drevet med forskning rundt dette temaet i tidligere Jugoslavia og fant at medieoverførte traumer øker antall psykosomatiske sykdommer, spesielt stress ulcus (bløende mavesår), hjerteog hjerneinfarkter (3). Folk som ikke har deltatt aktivt i krigen ble rammet av slike sykdommer mer enn de som har deltatt $\mathrm{i}$ krig fra det samme miljø.

Nye teorier viser til nødvendigheten av en defensiv orientert respons i farlige situasjoner $(4,5)$. I overført (sekundær) traumatisering finnes ikke de defensive responser. Aktivering av det autonome nervesystemet er til stede, men hjelpeløshet blokkerer forsvaret. Kort sagt: Det finnes ikke egnet forsvar for de som rammes av medieoverførte traumer. Forsvarssystemene deres blir overbelastet og utslitt i det lange løp.

Jeg mener det er viktig at både mediene og helsepersonell forstår dette. Det er mulig at bilder og tekst som utløser adrenalinrespons kan virke nedbrytende på helsen for noen.

\section{Sarah Zorica Mitic}

zormitic@gmail.com

Sarah Zorica Mitic (f. 1956) er overlege i anestesi ved Oslo universitetssykehus og SE traumeterapeut.

Ingen oppgitte interessekonflikter.

\section{Litteratur}

1. Høye S. Kommuniserbar sykdom. Tidsskr Nor Legeforen 2015; 135: 209

2. Gina Ross. The media and the understanding of the trauma vortex at the political level. Los Angeles, CA: Trauma Healing Institute, 2010.

3. Mitic ZS. Stress ulcus som utrykk for psykisk stress under krigsomstendigheter i Smederevoområdet (Serbia) i perioden 1990-1993. Mastergradsavhandling. Beograd: Tverrfaglig Institutt, Universitet i Beograd, 1995.

4. Levine PA. Somatic experiencing trauma institute. http://traumahealing.org/ (9.3.2015)

5. Porges SW. The polyvagal theory: neurophysiological foundations of emotions attachment, communication, and self-regulation. New York, NY: Norton, 2011

\section{Re: Kjernejournalen som arbeidsverktøy?}

Kommentarartikkelen «Kjernejournalen som arbeidsverktøy» konkluderer med at «Journalens endelige form må utformes gjennom prosjekter både i og utenfor sykehus» (1). Barnehjerteseksjonen, Rikshospitalet (BHS-RH), har siden 1990 hatt sin egen elektroniske journal Berte (navnet dannet av ordene Barne-hjerte) for pasientgruppen barn med hjertefeil/hjertesykdommer. 25 års erfaring med denne viser at det ikke nødvendigvis behøver å være konflikt mellom en komplett journal og en oversiktlig journal.

I Berte er kontaktlinjen er et sentralt element. En kontakt kan være en konsultasjon, en behandling, en telefonsamtale, et røntgensvar, en innkommet epikrise, en tanke osv. Det opprettes en ny kon- taktlinje hver gang det skjer noe vis à vis pasienten. Bertes motto er: «Data skal registreres der de oppstår når de oppstår». Derfor blir en kontaktlinje opprettet omgående av den i teamet som står for kontakten. I kontaktlinjen skrives det vesentlige ved kontakten i telegramstil med ca. 80 tegn til rådighet. Eksempelvis: «Spt-fri, card.bilyd. m-VSD, henv. op». Ved å rulle seg nedover kontaktlinjene på skjermen får man kjapt en god oversikt over pasientens sykehistorie.

Kontaktlinjene er gruppert i kontakttyper, eksempelvis «konsultasjon», «operasjon» etc. Ved et tastetrykk kan man velge om man ønsker å lese eller skrive ut på papir kontaktlinjene for alle kontakttyper eller for bare et utvalg av disse.

Til hver kontaktlinje kan det knyttes en eller flere journalsider. Dette kan være det komplette skrevne journalnotat, en mottatt epikrise, et foto, en EKG-registrering osv. Journalsidene er skjult, inntil man ved et museklikk på kontaktlinjen aktiverer den aktuelle journalside.

Hver gang en pasient åpnes i Berte, møter man et vindu med Resymé, dette viser hele pasientens samlede sykehistorie på én linje. Eksempelvis kunne denne være slik: «VSD op+ reop. Liten AoI. CoA». Dessuten finnes et eget meget i øyenfallende felt med viktig informasjon om medikamentintoleranse $\mathrm{mm}$.

Ved denne kombinasjonen av stikkordsmessig informasjon, som er meget oversiktlig og lett tilgjengelig, og komplett informasjon, som er logisk tilordnet den stikkordsmessige og som enkelt fås frem med et tastetrykk, har BHS-RH fătt et journalsystem som tilfredsstiller kravet til samtidig oversiktlighet og fullstendighet. Streng og kontinuerlig internjustis har medført at det å holde Berte oppdatert til en hver tid er blitt en selvfølge.

I Berte finnes også en alarmfunksjon som sikkerhet mot at noen pasienter faller ut av oppfølgning. Ved hver kontakt justeres alarmdato, og når en satt alarmdato overskrides, utløses automatisk en alarm. Berte har for øvrig mange andre aspekter som gjør det hensiktsmessig i daglig bruk, for eksempel ferdigdefinerte rapporter og rapportgenerator egnet til forskning, osv.

Berte ble utviklet i 1989 av Victoria Data, firmaet som senere ble til DIPS, og disse sto for en signifikant oppgradering av Berte til Windows-basert program i 2002. For brukerne er det derfor mange likhetspunkter mellom Berte og DIPS. Kombinasjonen av øyeblikkelig oppdatering, oversiktlighet og fullstendighet har gjort Berte til en brukersuksess (2) i en klinisk setting med stort pasientgjennomtrekk og svært mange kontakter til og fra andre instanser.

\section{Petter S. Hagemo}

pshagemo@broadpark.no

Petter S. Hagemo (f. 1943) er spesialist i pediatri, mangeårig overlege ved Barnehjerteseksjonen, Rikshospitalet, nå pensjonist.

Ingen oppgitte interessekonflikter.

Litteratur

1. Haffner J. Kjernejournalen som arbeidsverktøy? Tidsskr Nor Legeforen 2015 135: 112 .

2. Andersen R. Berte - en case-studie ved Barnehjerteseksjonen på Rikshospitalet. Prosjektrapport i IN364. Oslo: Institutt for informatikk, Universitetet i Oslo, 1997.

\section{J. Haffner svarer:}

Jeg er imponert over at Barnehjerteseksjonen på Rikshospitalet innførte en betydelig forbedring av journalen allerede i 1990. Så vidt jeg kan forstå er den viktigste forbedringen for oversikten det som står i 5. avsnitt: «Hver gang en pasient åpnes i Berte, møter man et vindu med Resymé, dette viser hele pasientens samlede sykehistorie på én linje. Eksempelvis kunne denne være slik: «VSD op+ reop. Liten AoI. CoA». Dessuten finnes et eget meget i øyenfallende felt med viktig informasjon om medikamentintoleranse $\mathrm{mm} . »$ Hvis journalen skal være allmenngyldig, tror jeg imidlertid at det er 